\title{
Apuntes para un Estado del Arte sobre Televisión y Familia
}

\author{
Luis Alfonso Guadarrama Rico \\ Centro de Investigación y Estudios Avanzados en Ciencias Politicas y \\ Administración Pública UAEM
}

\section{Los inicios}

En los albores de la década de los setenta, Betchel y sus asociados emprendieron un estudio para tratar de documentar los comportamientos de veinte familias, durante el tiempo destinado a la "inspección de la televisión". La forma de acercamiento fue realizada con equipo de grabación colocado en la sala de cada uno de los hogares de las familias participantes, con el objeto de captar las reacciones personales y las conversaciones de la audiencia durante la emisión de programas de televisión.

Los resultados de este estudio permitieron dar cuenta de algunas características del contacto visual, movimiento físico y modelos de conversación durante el tiempo de recepción. Las conclusiones de la investigación permitieron entender que ver televisión no ocurría en el vacío, que era siempre -en cierto grado- el fondo de un complejo patrón de comportamiento en el hogar (Cf. Lull, 1990). Las limitaciones de esta forma de acercamiento para tratar de estudiar a la televisión en la familia, pronto fueron puestas en evidencia, no sólo por los costos que implicó el uso de estos dispositivos tecnológicos, sino porque las modificaciones comportamentales de las familias eran considerables, en tanto se sabían filmadas y grabadas. Este primer estudio dio pauta para que los interesados en el conocimiento del fenómeno televisivo inscrito en el ámbito familiar buscaran formas más naturales de aproximación al escenario familiar.

Fue necesario que el llamado modelo de efectos y de usos y gratificaciones, poco a poco fuera puesto en el banquillo de los acusados a lo largo de toda la década de los setenta y los primeros años de los ochenta, para comprender que el fenómeno "ver televisión" reclamaba de un andamiaje más vasto que, alimentado desde la antropología, la sociología, la psicología, la

1 Betchel, R, Achelpohl, C, y Akers, R. eran un grupo de investigadores de la Fundación de Salud Mental de la Ciudad de Kansas, EUA. (Cf. Lull, James, 1990) 
lingüística y/o el psicoanálisis ayudara a desarrollar una mejor comprensión de este fenómeno de la comunicación.

Uno de los principales estudiosos del fenómeno televisivo en y desde la familia, ha sido James Lull. Su producción más importante puede ser ubicada -justamente- a partir de los primeros años de la década de los ochenta y lo que va de los noventa, pero sus trabajos iniciales datan desde 1975, año en que hizo estudios sobre recepción de la televisión con familias de Wisconsin, Estados Unidos. Es un autor que puede ser ubicado en la escuela de los estudios culturales, con especial énfasis en la investigación empírica cualitativa de las audiencias televisivas. Los resultados que a continuación presento están basados en un texto publicado en el año de 1990, debido a que condensa en el gran parte del material acumulado durante los primeros siete años de los ochenta.

En mi opinión, James Lull representa un parteaguas en el ámbito de la temática que aquí me ocupa y creo que varias de las aportaciones generadas por él, han servido como punto de referencia de estudios posteriores sobre el tema, sin que ello signifique el menor demérito de investigadores importantes como David Morley, Guillermo Orozco, Martín-Barbero, Irene Goodman y Hope Jensen, entre muchos otros. Por esta razón, dedico varias páginas a detallar algunos de los planteamientos y resultados de Lull, con el ánimo de establecer puntos de partida sobre lo que hoy sabemos respecto al binomio televisión-familia.

El interés de Lull está centrado en investigar, cómo a partir de la recepción televisiva en la familia se puede leer la doble relación sociedad-familia, familia-sociedad. Uno de sus trabajos recientes versa sobre la vida familiar con la televisión, en la República Popular China. ${ }^{2}$

La vinculación entre las prácticas de las audiencias televisivas en el ámbito familiar y su relación con fenómenos macrosociales, conducen a Lull a buscar en la teoría de la estructuración de Anthony Giddens ${ }^{3}$ parte de su andamiaje teórico-metodológico para poder explicar cómo las familias articulan, reproducen, transforman y trascienden en sus prácticas rutinarias de la vida diaria, los dominios de la economía, la política y la cultura. Ello puede ser observado -afirma Lull- si estudia de cerca a las familias, "prestando especial atención a su contacto con la televisión y a sus conversaciones dentro

2 Estudio etnográfico con 85 familias en Beijing, Shangai, Guangzhau y Xian, para tratar de dar cuenta de cómo los miembros de las audiencias chinas respondieron a una serie de televisión denominada New Star Cf. Lull, James (1988). Family Television.

3 James Lull, cita uno de los textos de Anthony Giddens: The Constitution of society" y refiere que en la teoría de la estructuración encuentra una nueva forma de ofrecer una perspectiva general sobre la actividad de la audiencia de los media. (Cf. Lull, 1992). 
y fuera de casa, y observando sus hábitos, los límites de la acción social que ellos construyen y sus estrategias interpersonales" (Lull, 1990:160).

\section{El trabajo etnográfico de James Lull}

La forma de trabajo de Lull es etnográfica, organizada alrededor de la observación participante; el uso de informantes y las entrevistas en profundidad. Esta triada -en palabras de James Lull- tiene el objeto de permitir al investigador comprender tanto como sea posible y con la mínima perturbación la "perspectiva nativa” (Lull, 1990).

Las familias que Lull ha logrado conseguir para realizar sus estudios son contactadas a través de instituciones religiosas, educativas, grupos de servicios, clubes o lugares de trabajo de alguno de los miembros; estrategia que le ha permitido obtener cierta homogeneidad en los grupos familiares y una puerta de entrada para ganar la colaboración de cada familia. Los objetivos de sus estudios son expresados a las familias participantes, en términos de un interés por conocer la comunicación en familia o la vida en familia, sin hacer referencia alguna a los medios masivos o la inspección televisiva, con el propósito de evitar posible sesgos en el desarrollo de las actividades de los miembros de esta unidad natural.

El investigador advierte que del número de familias inicialmente interesadas en tomar parte en la investigación, regularmente de un 25 a 35 por ciento sostiene su compromiso de colaboración; el resto arguye distintas causas de indisposición. Pero, sobre el número de unidades familiares que participan -reporta Lull- "entre un 10 y 25 por ciento no provee datos válidos para su incorporación al análisis, razones por las que el sobremuestreo se hace, siempre, indispensable" (Lull, 1990: 176).

Una vez que, en definitiva, las familias han aceptado que su escenario sea investigado para conocer "la comunicación en familia", el propio Lull o alguno de sus auxiliares de investigación se trasladan, por un período de tres a siete días, a vivir a la casa de cada unidad familiar, con el objeto de documentar el estudio de la audiencia televisiva. En general, se opta por observar durante siete días, divididos en tres etapas, con propósitos diferenciados en cada una.

La primera etapa de observación, que puede durar dos días, se destina a documentar las características de la casa-habitación, su mobiliario, objetos de ornato, herramientas, aparatos electrodomésticos, ropa y, particularmente, la localización de los televisores, radios y equipos similares. También se procura destinar parte de esta etapa al registro de la historia de la familia y datos biográficos de cada uno de sus miembros. Lull acota que en esta primera fase 
es de especial importancia hacer anotaciones respecto a lo que él denomina "aspecto psíquico" del medio ambiente y la apariencia física de los espacios familiares, debido a que esta impresión inicial puede ser de utilidad para ulteriores análisis.

Del tercero al sexto día, indicados como la segunda etapa de estudio, se orientan a observar y registrar secuencias de interacción, rutinas familiares, hábitos de comunicación y usos particulares de los medios. Durante esta etapa, el etnógrafo que estudia las audiencias televisivas, -indica Lull- debe conseguir entender "al actor y la escena de la acción" para poder interpretar adecuadamente los registros realizados durante todo el proceso de análisis y documentación. También destaca la importancia de que el investigador procure establecer un clima de confianza con la familia y sugiere, para ello, tomar parte en las actividades que realizan algunos de los miembros de la familia, pero siempre pendiente de no alterar las rutinas familiares. Esta práctica también permite que el etnógrafo pueda formular algunas preguntas claves pero en un ambiente informal o relajado (Lull, 1990).

Hacia el séptimo día, la estrategia seguida por James Lull, abre la tercera etapa en la cual se llevan a cabo entrevistas en profundidad, para lo cual se emplea la grabación en audiocasete. El autor aclara que la relación establecida con la familia durante los días precedentes, configuran un clima inusual y favorable para la realización de las entrevistas.

Lull reporta haber observado actitudes positivas y amplia disposición entre sus entrevistados, para expresar libremente opiniones, dar cuenta de creencias y juicios acerca de los otros miembros de la familia y, en general, con respecto a las interrogantes que formulan él o sus auxiliares. Complementada la información de cada unidad familiar, procede a realizar el análisis de los datos, alrededor de la o de las hipótesis que previamente y durante el proceso de investigación ha formulado.

\section{Usos sociales de la Televisión}

Los resultados de Lull permiten analizar cómo determinados procesos de selección, así como los patrones de interacción familiar; constituyen un reflejo de usos sociales más amplios. Así, la televisión en el contexto familiar puede ser empleada de dos maneras primarias: una estructural y otra relacional. Dentro de la primera forma (estructural) se pueden encontrar dos usos fundamentales: como medio ambiente, es decir, la televisión se mantiene como un ruido de fondo, a manera de compañía o bien como entretenimiento; como elemento regulativo, esto es, la programación televisiva permite marcar tiempo y 
actividades como las horas de alimento, horas para dormir, quehaceres y períodos de tareas.

Por su parte, la forma relacional puede estar conformada por cuatro tipos de usos. Como facilitados de la comunicación en tanto que las historias y los temas abordados por la televisión pueden ser empleados por los observadores para facilitar o abrir conversaciones entre ellos. Lull ofrece ejemplos que pueden inscribirse dentro de este uso social. Cuando explica que los niños frecuentemente utilizan la televisión para estar en posibilidades de intervenir en conversaciones de adultos o en patrones de expresión. A veces, encender la televisión cuando llegan invitados crea un terreno común puesto que "los extraños" en el hogar tienen posibilidades de intervenir en "pláticas de televisión", permitiendo con ello que los miembros de la audiencia comenten o discutan tópicos de experiencias comunes. O bien visto que el contenido de algunos programas televisivos resultan en algunas ocasiones controversiales, genera que individual o interpersonalmente las actitudes y valores de la audiencia familiar se vean interpelados por algunos de sus miembros, generando dicha clarificación.

El segundo uso social referido como afiliación/anulación interpersonal permite explicar, de acuerdo con Lull, distintas escenas que suceden con y entre los miembros de las familias. Hay quienes estando frente a la pantalla chica, parecen configurar un contacto físico especial o una intimación que aparentemente indica que no necesitan compañía o conversación alguna, aún a pesar de que otros miembros de la familia circulen o estén a un lado de ellos. El autor menciona como punto de referencia a un obrero que tenía una jornada de trabajo pesada y habitualmente se quedaba dormido cuando "veía la televisión de noche", "cabeceaba mientras estaba en su silla mecedora, sin zapatos, roncaba fuertemente con la boca abierta, en tanto su esposa permanecía sentada en el suelo en el mismo cuarto y se aproximaba hasta estar cerca de él, disfrutando de este momento de intimidad" (Lull, 1990:38). También dentro de este uso social se inscriben escenas en las que pueden sucederse tanto comentarios entre los miembros de la familia para mantener la relación y el contacto verbal y visual, como para reducir en ocasiones conflictos generados por otros motivos.

Lull refiere que desde el año 1972, la televisión ha estado ampliamente catalogada como un recurso de aprendizaje social, constituyendo así un tercer tipo de uso. Si se considera que mucha información para la vida diaria es decantada por los medios de comunicación electrónica, entonces, se genera un proceso de imitación respecto de ciertos tópicos presentados por la televisión para ser aplicados potencialmente en la educación de los hijos; la forma de 
vestir; nuevos productos para uso doméstico, etc. El autor también señala, que a través del contenido televisivo se transmiten valores, se gestan procesos de legitimación sobre asuntos políticos y, aún a pesar de la dispersión informativa que caracteriza a la televisión suele convertirse en un sustituto escolar para infantes de educación preescolar y básica.

El último tipo de uso social que define Lull se refiere al de competencial dominio. En este sentido, señala diversas situaciones en la que los miembros de las familias, pueden ver representados simbólicamente en las pantallas roles de los personajes que contribuyen a confirmar y reafirmar papeles similares que suceden en la propia familia. Sin embargo, ello no significa que las audiencias familiares, sólo estén a la caza de los mismos para reforzar lo que sucede en la familia, sino que también algunos contenidos televisivos pueden constituir pretextos para que algunos miembros de la audiencia familiar expresen tanto sus desacuerdos con respecto a dicho contenido así como los argumentos que hagan saber al resto de sus congéneres que tienen la "calificación o autoridad" para disentir y aún para burlarse de lo que sucede y se expresa en la televisión.

No menos frecuentes son las escenas en las que miembros de la familia del género masculino pueden reprobar los roles femeninos presentados por la televisión, por considerar que dichas acciones deben ser realizadas por sus similares. ${ }^{4}$ Dentro del mismo uso social competencia/dominio, al interior de las familias, se pueden apreciar otras formas de dominación interpersonal involucradas con la pantalla chica; por ejemplo, ver televisión en muchos hogares es concedido o retirado de manera autoritaria en función de recompensas o castigos.

La taxonomía de usos sociales que propone Lull, fue producto de un examen acumulado desde 1976 sobre registros observacionales de comportamientos de la audiencia familiar. Y aclara que dicha tipología no implica un orden particular y deben ser considerados cada uno de los usos de manera ordinal e interdependientes. De hecho, el interés del autor consiste en emplear la taxonomía como grandes divisiones y a caso puntos de referencia para estar en posibilidades, vía la investigación, de identificar tipos de televidentes o tipos de familia, en función de los usos sociales que dominan en los escenarios domésticos o bien aquellos, que identifican y conviven en ciertos miembros de la familia y entre ellos. Con base en lo anterior, Lull estima que es posible dar cuenta de estilos y estrategias de comunicación familiar y comprender así los usos particulares que las familias hacen de la televisión.

4 James Lull hace alusión al programa "Los Ángeles de Charlie" en el que los adolescentes criticaban, estando sus hermanas en el mismo cuarto, a las detectives mujeres por estar haciendo "un trabajo de hombres" (Lull, 1990: 43). 
Otro de los ejes de análisis empleados por James Lull durante sus investigaciones etnográficas sobre televisión en la familia está referido a las reglas empleadas para ver televisión. Considera que las familias emplean alternada y/o simultáneamente tres tipos de reglas: habituales, paramétricas y tácticas.

Las reglas habituales dan cuenta de cómo los padres pueden impedir a ciertas horas, que los niños o sus hijos adolescentes vean la televisión o determinados temas; también sirven para comprender el hecho de que algunos padres que trabajan se atribuyen el derecho de seleccionar programas de televisión en la noche, por considerar que es el tiempo cotidiano que tiene disponible durante la semana para "ver televisión", condición que se transforma en una recompensa no negociable con el resto de la familia. Otras manifestaciones de este tipo de reglas consisten en ver programas repetidos en la pantalla chica, si se consideran preferidos por algún miembro de la familia que tenga autoridad y que se haya ganado dicho privilegio. En otras palabras las reglas habituales están representadas en patrones de interacción rutinarios con la televisión y difícilmente son discutidos. Por ello, este tipo de reglas frecuentemente son creadas por los padres y parientes mayores.

Las reglas paramétricas, sirven para identificar formas de ver la televisión pues determinados miembros de la familia están en posibilidades de seleccionar programas favoritos, o bien de reservar el uso del televisor para restablecer conversaciones, comentarios, o discusiones en tanto se presentan anuncios publicitarios o bien intermedios. En menos palabras, las reglas paramétricas permiten encuadrar cierto tipo de comportamientos permitidos entre los miembros de la familia y que están sujetos a negociaciones flexibles entre los interactuantes.

Finalmente, las reglas tácticas aplicadas para ver la televisión en los espacios domésticos pueden ser consideradas como las interacciones que se desencadenan entre algunos miembros de la familia para lograr un objetivo personal o interpersonal. James Lull apunta, a manera de ejemplo, que un marido puede renunciar a ver su programa favorito como una manera de fortalecer o mantener la armonía con su pareja, o bien, como una forma de mostrar afecto y preferencia por alguno de sus hijos.

De esta manera, Lull deja en la mesa una propuesta que, basada en reglas y tipos de usos sociales puede ayudar en la difícil tarea de observar empíricamente a las unidades familiares y sus integrantes, con el objeto de trazar tipos de familias y tipos de televidentes. Como se ha anotado, el interés último de James Lull, es tratar de ofrecer un análisis acerca de los procesos de estructuración entre las prácticas televisivas que ocurren en el espacio de las familias y cómo éstas constituyen un reflejo de procesos socioculturales más amplios. 


\section{Sistemas familiares y televisión}

Otro de los enfoques teórico-metodológicos especialmente importantes sobre el tema es planteado por Irene Goodman. Ella ha desarrollado importantes trabajos de investigación sobre las formas de ver televisión y en particular ha enfocado su perspectiva conceptualizando a las familias como sistemas. A este respecto Irene Goodman insiste en la necesidad de investigar la forma en cómo la familia construye sus usos del aparato telerreceptor. Si bien aclara que los programas de televisivos, dada su propia estructura, generan significados, reglas, y valores cuando entran al hogar, en realidad "cada familia interpreta el televisor en sus propios términos y a través de su propia escena de reglas familiares (generando) un tipo de proceso de asimilación/acomodación familiar" (Goodman, 1983:407).

Uno de los ángulos que la investigadora ha observado con especial énfasis, está relacionado con observaciones de la conducta familiar en tomo a la mesa del comedor como punto focal para explicar la manera en la que éstas funcionan. Con ello, señala que determinados hábitos a la hora de la comida, pueden ser interpretados en términos de reglas que gobiernan la organización alrededor de la mesa: como quién cocina, quién prepara y sirve determinados alimentos y cómo se conducen las conversaciones a la hora de comer, constituyen -en términos de reglas- un paralelismo con respecto a lo que sucede en los hogares durante la recepción televisiva. La autora da cuenta de patrones de ubicación respecto al aparato; miembros de la familia que eligen programas; tipos de conversaciones suscitadas antes, durante y después de apagar el televisor (Goodman, 1983).

En los términos planteados por Goodman, cuando la televisión constituye un medio empleado frecuentemente para evitar o interrumpir la comunicación en la familia, ha de interpretarse como un síntoma de desequilibrio en el sistema familiar global y no como una conducta social aislada, dado que "ver televisión" y la comunicación interpersonal, forman parte de una dinámica interaccional, incrustada en la cotidianidad de la propia familia. (Goodman, 1983)

Es importante destacar la apreciación que hace esta autora acerca de la necesidad de entender que la familia vive transformaciones a lo largo del tiempo. De esta manera, se puede esperar que la televisión sea empleada de diversas maneras dependiendo de la fase de desarrollo familiar en la que se encuentre cada hogar, visto que las reglas y la toma de decisiones necesitan ser revisadas continuamente de acuerdo con el nivel de entendimiento y desarrollo de sus miembros, así como de las necesidades que presenta la unidad 
familiar en su conjunto; puesto que no se pueden emplear las mismas reglas para un niño de 10 años que para alguien de 19 años.

El trabajo referido es doblemente importante debido a que por vez primera las reglas que ayudan a comprender determinados comportamientos relacionados con "ver televisión” son -digamos- vistos a la luz de las dinámicas familiares y, además, se llama la atención sobre la necesidad de considerar que las familias jrasan por estadios o ciclos que constituyen el caldo de cultivo de esas dinámicas. De este modo, el investigador se puede encontrar con reglas $\mathrm{X}$ y W en la familia A, pero a cuatro o cinco meses de distancia, en la misma familia A, puede registrar la existencia de reglas Q y P, debido, por ejemplo, al desarrollo etéreo de cada integrante, o la partida de uno de los congéneres o incluso en atención al arribo de un nuevo miembro de la unidad doméstica.

\section{Espacios privados y televisión}

En un estudio, Hope Jensen et. al., mencionan cómo operan los contextos familiares de la televisión. Los autores indican que "cuando un aparato (de televisión) está en un área abierta a la mayoría de los miembros de una familia, comúnmente surge la pregunta acerca de quién tiene derecho a estar presente y quién tiene prioridad de elegir lo que van a ver" (Jensen, et al., 1985: 34).

A decir de los autores referidos, algunos espacios arquitectónicos en los hogares son físicamente y en términos de audiencia, más abiertos que otros. Hay casa-habitación en las que virtualmente no existe un lugar en donde se pueda ver televisión sin que se escuche en el resto de la casa y, en cambio, otros hogares -también arquitectónicamente hablando-- hacen posible que el ver televisión se convierta en elemento aislado, separado de otras actividades.

En este sentido, Jensen estipula que el número de televisores no constituye un referente significativo para explicar algunas maneras de ver televisión, sino que más bien la ubicación con su estructura física, el mobiliario y lo que constituye los centros de actividad cotidiana en el hogar conforman puntos focales para analizar la manera en la que se interactúa con la televisión. Por ejemplo, algunas familias ubican deliberadamente los aparatos televisivos en las cocinas porque es ahí donde los integrantes de éstas se reúnen a comer o a cenar y generan escenas gregarias, acompañadas de la recepción televisiva (Jensen et al., 1985).

Además de ello, Jensen y sus colaboradores descubrieron reglas explícitas o implícitas sobre actividades básicas de la familia como: comer, dormir, cocinar, limpiar y la realización de tareas escolares con respecto a la televisión. En algunos hogares las familias mantenían reglas que permitían 
la coexistencia entre televisión y alguna de estas actividades, mientras que otras marcaban una clara y excluyente relación (Jensen, et al., 1985).

Aquí, Jensen agrega al corpus del conocimiento la importancia de tener en consideración los aspectos territoriales del espacio familiar, es decir, cómo está diseñada intencional o fortuitamente la casa en la que habita la familia, visto que este aspecto contribuye a mejorar la comprensión del ambiente familiar y permite dar cuenta de reglas y pautas de interacción entre quienes conforman cada unidad.

\section{Género y televisión}

El mismo Lull había hecho mención de que sus hallazgos apuntaban a que el padre es la persona que generalmente tiene el control del programa que verá la familia (Lull, 1992), pero es David Morley, quien presenta un análisis de las prácticas de expectación genéricamente determinadas y de las dinámicas familiares, a través de las cuales ofrece una interpretación del contexto familiar y cómo éste debe ser empleado para buscar entender las formas de ver televisión (Morley, 1986).

El autor expone que hay claras diferencias entre los hábitos televisivos de hombres y mujeres en el contexto de los hogares, y señala que socialmente el modelo dominante en el hogar está definido primariamente por el hombre como un sitio de descanso, de esparcimiento, en tanto que para la mujer es un lugar de trabajo, al margen de si cuenta con un empleo remunerado o no. Así, el hombre ve televisión para descansar; porque así lo quiere. La mujer, en cambio, debe hacerlo de manera intermitente para evitar caer en el descuido de lo que -socio-culturalmente- está aceptado como "sus obligaciones" domésticas (Morley, 1992).

De este modo, es Morley quien profundiza en el análisis del poder dentro del espacio doméstico y lo aborda desde una perspectiva de género y amplía con ello la comprensión respecto a las reglas que operan en el momento decidir quién decide qué programas ver y permite entender parte de las raíces que alimentan formas distintas de interactuar con la televisión y con los programas que hombre y mujeres suelen mirar en sus hogares.

Vale acotar que últimamente el propio David Morley, junto Roger Silverstone, ha planteado que aún se sabe muy poco acerca de cómo las familias interactúan con la televisión en sus actividades cotidianas. Por ende, es el hogar de las familias el contexto más apropiado para la investigación de esta temática. Ambos autores han sostenido la necesidad de "estudiar las reglas o lógicas en uso del comportamiento cotidiano para poder comprender cómo son incor- 
porados y puestos en funcionamiento los diversos medios dentro de los mundos privados" (Morley y Silverstone, 1994:73). Para arribar a este propósito los mismos investigadores subrayan como condición indispensable para facilitar la comprensión del contexto que ocupa la televisión o cualquier otra tecnología de comunicación en el hogar, "entender las dinámicas familiares, las estructuras de la vida diaria y el sistema familiar" (Morley y Silverstone 1994:73).

\section{Mediaciones y telenovela, la propuesta latinoamericana}

Hacia el año de 1986, Jesús Martín-Barbero dio inicio a un amplio proyecto de investigación que busca "indagar las mediaciones ${ }^{5}$ en las cuales se materializan las constricciones que vienen de la lógica económica e industrial en su articulación con las demandas y los modos de ver de diferentes grupos sociales" (Martín-Barbero, 1992: 20).

Este proyecto estuvo alimentado conceptualmente por una serie de avances importantes, que confirieron una nueva manera de entender a la televisión y de construir objetos de estudio para la investigación en América Latina. Como el propio Martín-Barbero lo marca, destacan los trabajos de García Canclini sobre consumo cultural; las aportaciones de De Certeau y su teoría de los usos sociales, así como las contribuciones de Bourdieu, en particular sobre el concepto de hábitus y de capital (Martín-Barbero, 1992). Con estos ejes, Martín-Barbero formula una serie de interrogantes necesarias para tratar de comprender de mejor forma a la televisión, y propone un amplio proyecto encaminado a explorar distintos ángulos del melodrama televisivo, desde aspectos como la competitividad industrial, pasando por las rutinas productivas y las estrategias de comercialización hasta los usos sociales y modos de ver la telenovela. De este último (usos sociales), planteó tres áreas con sus respectivos abordajes metodológicos: hábitos de consumo de televisión y rutinas familiares; espacios de circulación y resemantización y competencias culturales e imaginarios colectivos.

5 De acuerdo con Martín-Barbero, las mediaciones son "ese lugar desde donde es posible comprender la interacción entre el espacio de la producción y el de la recepción lo que se produce en la televisión no responde únicamente a requerimientos del sistema industrial y a estratagemas comerciales, sino también a exigencias que vienen de la trama cultural y los modos de ver. (...) la televisión no funciona sino en la medida en que asume -y al asumir legitima- demandas que vienen de los grupos receptores; pero a su vez no puede legitimar demandas sin resignificarlas en función del discurso social hegemónico" (Martín-Barbero, 1992: 20) Text of Footnote 
Brasil, Colombia, México y Perú, a través de algunos investigadores; se sumaron a este esfuerzo e iniciaron, en1989, un trabajo orquestado por la propuesta de Martín-Barbero. El proyecto referido constituye posiblemente una de las arterias que alimentó en estos países latinoamericanos la necesidad de tomar a la familia como unidad básica de audiencia y como situación primordial de reconocimiento.

Las estrategias de acercamiento instrumentadas por cada uno de los investigadores fueron distintas entre sí y acaso adaptadas tanto a las condiciones de factibilidad de cada uno de los escenarios y países, así como a los propios enfoques con los que buscaron enriquecerlo. Enseguida hago referencia a los reportes de investigación generados desde esta propuesta teórico-metodológica, atendiendo, en algunos casos, a la fecha en la que fueron realizados los estudios con el propósito de dar cuenta de los inicios de estas preocupaciones, con relativa independencia de su publicación.

\section{Familia, hábitos, rutinas y televisión}

Nora Segura, llevó a cabo un estudio de campo realizado en 1987, en el cual aplicó un cuestionario a 152 hogares de la ciudad de Cali, Colombia, estratificados de acuerdo a tres niveles socioeconómicos: bajo, medio y alto. El cuestionario contenía ítems para caracterizar el tipo de vivienda; la familia; condiciones ligadas a la forma de recepción de la televisión; tipo de programas que solían ver los miembros de cada familia; toma de decisiones frente a la televisión (estructura del poder familiar); fuentes de información distintas a la televisión; formación de opinión por la vía de la televisión y sintonía de telenovelas.

El estudio buscó que el cuestionario fuera resuelto por las amas de casa "por cuanto se postulaba que la centralidad de la mujer en el hogar la convertía en la televidente más propensa a lo largo del día y probablemente la persona mejor informada sobre hábitos y rutinas de otros miembros" (Segura, 1992: 180). La composición de las familias de la muestra era de 5 miembros, la mitad de ellas de estructura nuclear; casi un $20 \%$ de tipo extenso y un $22 \%$ con combinaciones de parentesco. ${ }^{6}$ Si bien se logró que un 70\% de las respondientes tuvieran la condición de amas de casa $a^{7}$ los resultados correspondieron a una óptica de mujeres (madres, hijas, tías, abuelas). ${ }^{8}$

6 En detalle, cuatro de cada diez informantes eran cónyuges; tres de cada diez, jefes de hogar y el 23 por ciento eran hijos.

7 El subrayado es mío.

8 En un 92 por ciento fue contestado por mujeres 
La autora realiza una serie de cruces de variables que pertenecen a los propios contenidos de los reactivos del cuestionario y separa la información por nivel socioeconómico y tipo de familia. De acuerdo con los propósitos de este capítulo, se mencionan algunas de las conclusiones de mayor interés:

Es imposible hablar de la familia (colombiana) a secas o de manera global, es necesario emplear la idea de tipologías familiares de base regional, más que un encajonamiento genérico de familia "urbana" o "nuclear".

- La televisión reúne a la familia y define una parte importante de los intercambios entre sus miembros.

- Parece que la función predominante de la televisión, es informativa, pues los noticieros de la noche capturan la audiencia más alta.

- El grado de diferenciación del espacio habitacional, el número de televisores disponibles y la cantidad de miembros que integran a las familias, así como el grado de incompatibilidad entre actividades y personas, constituyen el tejido que da cuenta de las formas de consumo televisivo y el tipo y modo de las relaciones entre los miembros de las familias.

- Ante las discusiones que suelen haber entre los hijos acerca de qué programa de televisión ver, es la madre quien arbitra la discusión o la resuelve por medio de la negociación.

- Los estratos económicamente más bajos, colocan en el lugar más abierto, más público al televisor; las familias ubicadas económicamente en la parte alta de la pirámide social, destinan un espacio más privado.

Ciertamente en el trabajo comentado arriba, se aprecia una importante concurrencia de elementos que tratan de una manera más amplia el fenómeno televisión-familia. Se observa el interés y reconocimiento por establecer como puntos de referencia: el estrato socioeconómico de las familias; el tipo de familia de que se trata, (nuclear o extensa); tipo de vivienda; preferencias programáticas de cada uno de los miembros; estructura de poder al interior del grupo privado y aún de otras fuentes de información que arriban a las familias.

Mi apreciación es, que el sentido y dirección con el que Nora Segura lee sus elementos en cuestión parecen mantener la óptica de que la televisión es la que genera determinados comportamientos. Dicho de otra manera, la televisión provoca que la familia se reúna, la televisión captura a la audiencia; la televisión atrapa de manera más frecuente (aunque de manera espasmódica) a las mujeres dedicadas a los quehaceres domésticos, y menos a los adolescentes y a los padres de familia. El comportamiento, en términos de selección 
o preferencias programáticas hacia la televisión y aún determinadas escenas frente o alrededor del televisor, resultan incuestionables pero creo que, en principio, priva en cada unidad familiar y aún en cada uno de sus integrantes una dinámica, un estadio y rasgos de personalidad propios ${ }^{9}$ que han de tenerse en cuenta para explicar de mejor manera la relación establecida con la televisión en una etapa o momento particular.

\section{Género, generación y consumo televisivo}

En el barrio de Cañaveralejo, a el suroccidente de Cali, Colombia, un barrio popular relativamente aislado por sus condiciones de acceso geográfico, Clara Llano, buscó dar cuenta de "la construcción social de la lectura de la telenovela..." (Llano, 1992: 215). También como parte del proyecto propuesto por Martín- Barbero, el estudio permitió dar cuenta de las rutinas cotidianas y la imbricación de éstas con la televisión en general y con las telenovelas en particular. Clara Llano, observa que "el tiempo dedicado a ver telenovelas depende del tipo de ocupación de cada uno de sus miembros (de la familia) y del empleado en las actividades de trabajo, estudio, ocio y diversión" (Llano, 1992: 222).

Los resultados de Llano se enfilan en el sentido, de que las mujeres que laboran en la casa tienen posibilidades de ver la televisión en la primera parte del día, pero este "ver televisión” sólo es para oírlo pues, como lo declaró alguna de sus entrevistadas, "Yo prendo el televisor y voy haciendo porque sino... desde aquí oigo y cuando hay algo emocionante voy a ver; como uno conoce los personajes, ya sabe quién está hablando" (Llano, 1992:223). Este aspecto le permite subrayar a la autora, que la recepción televisiva no significa necesariamente un momento particular para "sentarse frente al televisor" sino que puede ser combinado con mucl-ras otras actividades domésticas que no se contraponen a la llamada recepción televisiva y que en su caso, dichas labores pueden ser suspendidas cuando "algo emocionante" sucede en la telenovela en cuestión. Dicho sea de paso estos momentos "trágicos" o "impresionantes", han sido codificados históricamente mediante la musicalización, el tono de la voz que los personajes imprimen a su actuación o bien por el desarrollo que presenta la trama de la propia telenovela.

9 Por esta razón, como más adelante se verá en el trabajo de Clara Llano, una de sus entrevistadas expresa que cuando está metida en sus ocupaciones no le atrae prender el televisor, porque le disgusta ver una novela por pedacitos, posición que nos deja entrever cómo la personalidad de cada individuo también atraviesa ciertas pautas comportamentales con la televisión 
No obstante, como se comentaba en párrafos anteriores, esta cohabitación entre la televisión y las actividades cotidianas no está generalizada entre las mujeres que se ocupan de los quehaceres domésticos, pues quizá en función de sus preferencias y rasgos de personalidad, algunas -a pesar de tener pleno conocimiento de la emisión de programas de su preferencia, como pueden ser las telenovelas- no les gusta encender el televisor por la mañana, como algunas de las entrevistadas lo declararon "yo cuando estoy haciendo algo no me gusta prender el televisor (...) no me gusta ver una novela por pedacitos" (Llano, 1992:223).

Por las tardes, desde que inicia la emisión vespertina, el televisor es encendido independiente de lo que se vea, o no, un programa específico. Con base en el reporte citado, a esas horas la televisión es "vista" por las mujeres que realizan los quehaceres domésticos, por los niños, los y las jóvenes que llegan de la escuela; situación que apunta una constante circulación de personas por donde está el televisor. Como lo glosa Llano, algunas de estas personas mirarán lo que está puesto en el televisor y luego se retirarán; otros, en cambio, se quedarán atentos mirando el programa en cuestión y algunos más, platicarán mientras el televisor está encendido (Llano, 1992).

El estudio colombiano concluye que "el género y la generación son dos factores claves en el consumo de la televisión. Regularmente todas las mujeres, de diferentes edades, están de acuerdo en que las telenovelas son el género televisivo que más les gusta" (Llano, 1992: 224). A detalle, las mujeres jóvenes, quienes también muestran una inclinación por el melodrama, están pendientes cuando el contenido y los actores corresponden a su grupo etáreo, pero, además la autora se percató que las mujeres jóvenes gustan de los programas de aventuras, dibujos animados y musicales; en contraparte de la mujeres mayores que suelen preferir las películas como una segunda opción a los programas melodramáticos. (Llano, 1992).

En este sentido, Clara Llano hace notar que esta concurrencia de diferentes audiencias que parecen desfilar todos los días, en horarios específicos en .los hogares para mirar sus programas y géneros preferidos; configuran un ritualismo cotidiano que permite dar cuenta de una repetición continua que abstrae las diferencias selectivas de cada uno de los miembros de la familia.

\section{Educación, televisión y familia}

Como parte de un estudio cuyo propósito era contribuir a la comprensión de los medios de comunicación y la relación con la familia a través de los procesos que ésta refuerza, complementa, contradice o inhibe el impacto de 
la televisión en sus miembros, Leoncio Barrios, realizó una investigación etnográfica en Venezuela con tres familias; dos asentadas en el Barrio de Petare y la otra en el sureste de Caracas. Las familias seleccionadas por Barrios ${ }^{10}$ cumplieron con los siguientes requisitos: i). ser venezolanas en dos generaciones; ii). Tener al menos un televisor en casa; iii) ver televisión como una actividad cotidiana y, iv). Tener al menos dos niños con vocabulario adquirido, toda vez, que uno de los ejes de análisis del autor consistía en analizar la interacción entre los miembros de la familia y los pequeños. El trabajo de recolección lo llevó a cabo entre 1987 y 1988. El reporte fue presentado a finales de 1989 y publicado en $1993 .{ }^{11}$

Las familias estudiadas presentaron diferencias en cuanto a su estructura y composición. La primera fue de tipo extensa, con dieciséis personas (nueve adultos y siete niños) y un jefe de familia del sexo femenino cuya edad era cercana a los sesenta años. La segunda, de tipo nuclear, integrada por cuatro personas (un adulto, una adolescente, una niña y un niño) pero sólo con un jefe de familia del sexo femenino, cuya edad era de 34 años. La tercera familia de tipo nuclear, conformada por cinco miembros (dos adultos, un adolescente, una adolescente y un niño); ambos cónyuges con edades cercanas a los 40 años (Barrios, 1992).

El trabajo de recolección etnográfica fue realizado a lo largo de dos años -como el autor lo escribe- durante su "tiempo libre". Durante el primer año, el investigador visitó a dos familias un par de veces a la semana, por espacio de tres meses y, para el segundo año, aparte de mantener una agenda de trabajo similar con las familias anteriores; incorporó a su estudio a la tercera familia. El proceso de observación etnográfica tuvo "una duración total de setenta horas por familia, distribuidas en catorce semanas" (Barrios, 1992: 149). Los horarios de trabajo dentro de las familias fueron diversos pues oscilaban entre las ocho de la mañana y las diez de la noche, instrumentadas a manera de visitas en las cuales el autor observaba todas las actividades de los miembros de las familias y particularmente en referencia a la televisión, además de tomar notas de sucesos importantes, compilados para el análisis posterior.

10 El autor señala que una de las familias era conocida por él antes de la investigación; a la segunda tuvo acceso a través de la empleada doméstica de uno de sus amigos y esta segunda, le presentó a la tercera (Barrios, 1992: 148).

11 El estudio de Leoncio Barrios, constituyó su tesis doctoral, titulada Family and Televisión in Venezuela: an Ethnographic Study, presentada en la Universidad de Columbia, Nueva York en el año de 1989 Vale mencionar que esta investigación fue galardonada con el premio "Monseñor Pellin" 1990, como trabajo de investigación en el área de Comunicación Social. 
Parte de sus resultados señalan que la televisión puede tener, en efecto, un papel educativo en el contexto del núcleo familiar, pero no reside en el instrumento en sí mismo, sino que actúa y produce efectos dependiendo de las características particulares, tanto de la estructura predominante en la familia" como de variables que incluyen desde la organización espacial de la vivienda hasta los papeles que cada miembro desempeña en el grupo, sus nexos con el medio social externo, e incluso el lugar que ocupa en términos de posición por edad cronológica. Por ello, la conclusión del investigador estriba en que la televisión por sí misma, no es un elemento contra la comunicación de la familia o el desarrollo socio-cognitivo de los niños, sino que depende de los adultos y el uso que le den al aparato. (Barrios, 1992).

Las familias fueron analizadas tanto en sus hogares (condición socioeconómica, distribución espacial de los muebles y la ubicación estratégica de la televisión), así como las características propias de cada integrante (edad, personalidad, influencia que ejercen sobre otros miembros de la familia, tiempo y programas vistos). Un aspecto también importante para el autor, era el aprendizaje que se derivaba de la interacción con el aparato y las reglas que lo controlaban. Por ejemplo, Barrios encuentra que a determinados miembros de la familia se les prohíbe ver un programa en específico, aunque algunas veces las reglas sólo son para los niños: apagar la televisión cuando se realiza la tarea y no verla cuando hay visitas. Alguna o varias de estas reglas son violadas dependiendo del tipo de control que ejerzan los jefes de familia sobre el resto de los integrantes. En este sentido, como en el resto de las familias venezolanas, Barrios sostiene que se manifiesta un poder matrilineal por ser las mujeres las que están en la casa y las encargadas de tiempo completo de la educación de los niños, además de considerar a la televisión un objeto al mando de la mujer como cualquier otro utensilio de la cocina; dentro de esta influencia femenina, las abuelas también forman parte importante en la educación de los menores.

Los resultados de Barrios ayudan a fortalecer otros planteamientos más generales en el sentido de que "el ejercicio del poder en la familia, está en conexión con la estructura o forma de organización de la misma y en ello reflejan valores y patrones culturales..." (Barrios, 1992.: 97). De esta manera, en el reporte se entiende por qué en las dos familias cuyo poder está circunscrito a las mujeres que ostentan la jefatura del hogar, también regulan lo que se ha de ver y las condiciones asociadas al encendido y apagado del televisor. También se comprende cómo en la familia nuclear en la que ambos cónyuges contribuyen al sostenimiento económico del hogar, es el progenitor masculino quien toma la decisiones sólo que con una mayor influencia pues -a dife- 
rencia del hombre promedio venezolano- el referido por Barrios participaba activamente en las actividades domésticas, confiriéndole "un poder casi absoluto, incluyendo, por supuesto, lo que concierne a la televisión" (Barrios, 1992: 99).

El fenómeno del poder dentro de la familia y su relación con la toma de decisiones respecto a la televisión, llevan a Barrios a confrontar su análisis con algunas de las conclusiones formuladas por Morley, en sus estudios con familias británicas. Veamos. En tanto el investigador de la Universidad de Birmingham sostiene que el uso de la televisión sirve para afianzar el poder del hombre sobre la mujer y reproduce la frma en que cada uno ha sido socializado con respecto al otro (Morley, 1986), Leoncio Barrios llama la atención sobre el hecho de considerar algunos matices sobre tal afirmación, al menos cuando las familias son monoparentales cuyo jefe de familia es mujer.

En la misma línea del poder, Barrios coincide con Leichter y Cols, (1985) al señalar que es indispensable comprender la dinámica de cada familia para arrojar Luz sobre la llamada toma de decisiones respecto a la televisión, vista en que algunos miembros de la familia tienden a prender la televisión más que otros, por lo que pueden ser considerados como "iniciadores", pero esta identificación de "iniciadores" resulta demasiado tosca, cuando se observa que en varias familias suele ser un niño, a quien se hace el "encargo" de encender el televisor como -una medida para tranquilizarlo, o bien se puede tratar de una persona adulta desempleada quien, en tal condición, muestra una mayor proclividad a encender el televisor (Barrios, 1992).

Otras observaciones presentadas por el autor indican que algunos miembros de las familias poseen mayor "cultura televisiva" que el resto y ello les permite cumplir con el rol de "radares", en tanto que son los encargados de recordar a los otros miembros la transmisión de determinado programa, o bien generan mensajes (lingüísticos o paralingüísticos) para indicar que se tomen medidas ante el inminente comienzo de un programa. En paralelo, los registros indican a Barrios que también suele estar conformado un acuerdo implícito que organiza el uso de la televisión por turnos: en las tardes para los niños; las horas de telenovela para las mujeres y los domingos (en programas deportivos) para los hombres y las películas para todos (Barrios, 1992).

Las familias estudiadas hacen ver que (en éstas) no fue posible apreciar una clara frontera entre "ver" o "no ver" televisión, ya que podía estar prendida por mucho tiempo, sin que ello implicara que alguien la estuviese observando; es decir, "ver televisión" se diluye en el quehacer cotidiano, condición que evidencia -de acuerdo con Barrios- que "ver televisión" es "una actividad transicional, que no corresponde al tiempo comprometido y tampoco al 
tiempo libre" (Barrios, 1992: 132). El propio investigador llama la atención sobre el hecho que la televisión se puede encender para conciliar el sueño; mientras se hace el amor y también cuando se descansa o se toma la decisión de "voy a ver televisión".

La visión que ofrece Leoncio Barrios respecto del binomio televisión y familia, resulta mucho más integral que otros trabajos sobre el tema. Posiblemente su contacto con las principales vertientes que llegaban a la Universidad de Columbia (Nueva York), cuando en la segunda mitad de los ochenta iniciaba sus estudios de doctorado, le llevaron a plantear la necesidad de integrar distintos ejes para dar cuenta de su objeto de estudio. Quizá por esta razón ofrece diversos elementos como el papel de la estructura familiar, su dinámica, el tipo de vivienda, la organización espacial, el medio social que cultural y subculturalmente atraviesan a las familias y que configuran una buena parte de los roles que están prefigurados, o que se esperan, respecto de los hombres y las mujeres.

Todo esto contribuye a sentar las bases para entender --entonces- las reglas que operan las familias cuando "ven televisión"; el fenómeno del poder dentro del grupo privado y cómo este dominio presenta matices y un armazón que puede ser comprendido de mejor manera en la medida en que se desentrañe la dinámica de cada familia para descubrir que hay "iniciadores" y "radares" en determinadas unidades familiares y que "ver" o "no ver" televisión, no necesariamente está atado a un tiempo libre o comprometido ex profeso para ello.

\section{Vida cotidiana, televisión y familia.}

Ana Bertha Oribe publicó un artículo en el que adelanta algunas de las conclusiones sobre un proyecto amplio encaminado a indagar el mundo de las telenovelas, mediante investigación etnográfica. ${ }^{12}$

La propia autora comenta que muchas de las ideas planteadas derivan de ese proyecto y, a decir de ella, comparte la autoría con su dos colegas (Angélica Bautista y Karla Covarrubias).

El propósito del estudio era ofrecer tres ángulos de análisis: producción, composición textual y sus apropiaciones; trata de "descubrir qué es lo que la gente hace con la telenovela, cuáles son sus formas de relación con ella, sus

12 En el año de 1994, Ana Uribe, Angélica Bautista y Karla Covarrubias; publicarían un amplio texto, editado por la editorial Trillas, en el que desglosan su investigación etnográfica, con tres familias clasemedieras, asentadas en Colima. Por la importancia de este texto, más adelante se comenta con detenimiento los resultados y análisis reportados por las autoras 
modos de lectura y exposición ante el texto, sus propios criterios selectivos de recepción”. (Oribe, 1993: 188) Por las ideas que en dicho artículo expresa, enseguida se apuntan las de mayor interés:

- La relación de los telespectadores con la televisión está mediada por distintos elementos situacionales, institucionales y culturales.

- El receptor otorga el reconocimiento, la legitimidad a lo que ve; define y elige qué de los contenidos televisivos que recibe son verosímiles y cuáles no.

- Los miembros de la familia no mantienen una relación de exposición exclusiva o absorta con la televisión pues desarrollan diversas prácticas y acciones durante la exposición.

- En particular, con el género de la telenovela, las familias experimentan distintos niveles de involucramiento con la trama y su desarrollo. Así, la telenovela es un medio para sentir y reconocerse en situaciones presentadas durante la trama y el vehículo para apropiarse de acciones y valoraciones de otros mundos sociales, similares o considerablemente ajenos.

- El melodrama televisivo pone en contacto físico y comunicacional a los miembros que integran la familia. Durante estas escenas emergen y se desgranan los contactos afectivos (Uribe, 1993).

Estas conclusiones, como se ha señalado, tuvieron carácter preliminar y, posteriormente, el estudio completo fue objeto de publicación bajo el título: "Cuéntame en qué se quedó. La telenovela como fenómeno social", editado por Trillas. En dicho texto las tres autoras dan cuenta de su trabajo en forma pormenorizada. Enseguida un breve desglose.

En el trabajo señalado, Karla Covarrubias, Bautista y Uribe se propusieron "conocer cómo la gente usa y se apropia del género televisivo con mayor audiencia (rating) en la región: las telenovelas" (Covarrubias, 1994: 7-8). Para ello, mediante una estrategia de acercamiento etnográfico, eligieron tres familias que fuesen lo suficientemente abiertas como para aceptar la admisión de un "intruso" observador, (durante los cuatro meses que duró el desarrollo del trabajo etnográfico) y que vieran cotidianamente telenovelas.

$\mathrm{Al}$ revisar el estudio mencionado, se antoja un entramado teórico múltiple que, me parece, tuvo la intención de potenciar el análisis de los datos y registros etnográficos, pues la interpretación se apoyó en conceptualizar a la familia como un sistema (según la propuesta de James Anderson); mantuvieron como uno de los ejes la categoría de vida cotidiana, venida de los planteamientos de la neomarxista Ágnes Heller, colocaron en uno de sus ejes analíticos el concepto capital (capital social, capital económico, capital 
cultural) propuesto por Pierre Bourdieu y, finalmente conceptualizaron -a manera de triada- a la televisión como tecnología, según la definición expuesta por Graham Murdock; como agente social según la descripción de Jorge González y mediación de acuerdo a los planteamientos de Martín Serrano (Ver Covarrubias, et al., 1994).

La estructura de las tres familias asentadas en la ciudad de Colima era como sigue: una estaba compuesta por ocho elementos y tenían 35 años de haber iniciado su constitución como tal; la segunda, compuesta también por ocho elementos con prácticamente el mismo número de años de conformación y la tercera estaba integrada por seis individuos con diez años de vida familiar.

Encontraron que en las tres familias estudiadas, la televisión tenía tantos usos conscientes como inconscientes. En los primeros identificaron siete tipos: reguladora del tiempo, agente de compañía, agente consejero, medio que proporciona motivos de conversación, medio de entretenimiento y distracción, medio que otorga todo tipo de información, medio que propone modas, acciones y hábitos. Dentro de los usos inconscientes, reconocieron tres tipos: instrumento de poder en ciertas situaciones de la vida familiar, como medio de descalificación social y como medio de catarsis (Covarrubias, 1994).

Asimismo, los resultados del estudio mostraron que las rutinas de cada una de las familias, eran diferentes, pero coincidieron al momento de sentarse a ver la televisión. En la mayoría de los individuos que integraban cada familia, el tiempo de exposición televisiva alcanzaba la tercera parte de las actividades diarias dentro del hogar, el resto eran: comer, dormir, descansar, estudiar; necesidades fisiológicas, aseo personal y limpieza del hogar. Ello permitió conceptualizar que tanto los momentos de ocio como de actividad intensa de las familias, estaban dedicados a la práctica televisiva.

No obstante, la actividad de "ver televisión" es suspendida ante las denominadas situaciones limite como: un conflicto familiar, la enfermedad de uno de los miembros, el deceso de un conocido de la familia, alguna festividad religiosa o un compromiso laboral. En otras palabras, la televisión deja de ser el centro del entretenimiento y pasa a un segundo término hasta que -nuevamente- vuelve a ocupar su lugar. En el trabajo referido se explica también que el empleo del videocasete compite fuertemente con la práctica de ver televisión, sobre todo en períodos vacacionales, cuando los miembros de las familias, a través de la renta de películas, reducen su exposición a la oferta programática de los canales nacionales y locales aún cuando tácitamente no se pierde el contacto con el aparato televisivo (Covarrubias, et al., 1994). 
Otros frutos reportados manifiestan que las familias están moduladas por múltiples y variados flujos exógenos como el sistema educativo, medios de comunicación e instituciones políticas y religiosas; éstos conforman elementos que intervienen al momento de darle lectura a los melodramas televisivos; lo mismo puede decirse de los bienes acumulativos, intercambiables y heredados como capital específico del espacio social. Las autoras del estudio apuntan que en las tres familias se negocian situaciones y se marcan posiciones en lo que unos definen con respecto a otro, una acción particular y en otra se pueden cambiar los roles; lo que siempre sucede es el poder en la toma de decisiones, situación que también interviene al momento de la lectura del melodrama. En lo referente al espacio físico-social, se concluye que el principal lugar de convivencia familiar es donde se localiza el televisor.

Como las propias autoras lo expresan, apoyadas en las teoría sociológica de Bourdieu, ${ }^{13}$ cuando el individuo logra tomar distancia de su grupo de origen, es decir de su familia a través de otras instituciones sociales e ideológicas como la escuela, el trabajo, etc., se modifican sus perspectivas de percepción, de acción y de valoración del mundo y son éstas las que tamizan o modifican sus pautas de selección televisiva; aunque, como las propias autoras acotan, ello no implica la renuncia total a su grupo de origen (Covarrubias, et al., 1994).

Llama la atención el manejo de un concepto sistémico sobre la unidad de análisis que es la familia e involucra tanto a la estructura como la dimensión temporal de ésta así como la categoría situación límite. Sin embargo, creo que las autoras no mantienen la óptica sistémica cuando interpretan sus registros y observaciones etnográficos, no sólo debido a que se apoyan en las categorías hábitus, capital cultural, catarsis y usos inconscientes, ${ }^{14}$ sino porque dejan de lado conceptos claves como subsistemas, ciclos de vida y sistemas de coacción. Posiblemente su intención fue potenciar su análisis mediante el entrecruzamiento de distintas ópticas teóricas con el ánimo de ofrecer una comprensión acaso más densa de cada familia y del fenómeno en general. El hecho es, que la pretensión de conceptualizar a las familias desde la perspectiva sistémica, quedó un tanto reducida.

Sin menoscabo de lo señalado, desde mi punto de vista, el trabajo de las autoras logra un avance importante debido a que "instalan" en el núcleo del análisis a la familia, en su estructura, en el complejo devenir cotidiano de rutinas, tiempo libre, reglas, usos conscientes e inconscientes de la televisión; dan cuenta del poder en la toma de decisiones no sólo referente a lo que se ha de "ver", si no incluso en cuanto a lo que se puede interpretar, en particu-

13 En particular, retoman las categorías de habitus y capital cultural.

14 Estos últimos dos conceptos fueron entresacados de la teoría psicoanalítica. Ver Fenichel (1979). 
lar del género melodramático; también describen los escenarios espaciales que ocupan cada uno de los casos estudiados, así como la interrelación con otras tecnologías domésticas que conforman el hábitat de cada unidad. Digamos que constituyen un eco importante acerca de lo señalado por Morley y Silverstone (1994), en el sentido de la urgencia de contribuir a una mejor comprensión de la vida cotidiana y del contexto privado en el que se ve televisión.

\section{Mediaciones múltiples y el interés por los niños}

Preocupado por la relación entre televisión y educación infantil, Guillermo Orozco inició en 1987, una amplia investigación que, desde la perspectiva teórica de las mediaciones, ofrece aportes importantes para comprender los procesos de recepción en la audiencia infantil. La vertiente que desarrolla Orozco en México llama la atención sobre el hecho de que en el escenario familiar es donde se produce la primera apropiación de mensajes. En este ámbito, en palabras del propio Orozco "se produce una negociación sobre y a partir de la televisión entre los diferentes familiares y donde ciertas actitudes de los miembros mayores se manifiestan con mucha claridad" (Orozco, 1992:13).

A este respecto, dados los intereses del presente trabajo, resulta de especial importancia señalar que el receptor se enfrenta a la televisión con una serie de actitudes, conceptos, valores y en general un bagaje cultural que entra en juego antes, durante y después de establecer contacto con la televisión; generando así, que esta interacción (TV -receptor) resulte conflictiva y contradictoria. Por ello, como lo indica el autor, se genera un proceso de apropiación que presenta múltiples mediaciones: cognitiva, cultural, referencial, institucional y videotecnológica. Es decir, sostiene que la llamada recepción debe ser vista a la luz de un proceso atravesado por este tipo de mediaciones, pues son las que permiten comprender cómo, específicamente los niños aprenden a interaccionar con la televisión (Orozco, 1991a).

El trabajo de Guillermo Orozco ha contribuido a redimensionar la manera en que la televisión se articula con los procesos de aprendizaje en los infantes, pero además, ha permitido explicar el papel que juega la escuela a través de los docentes, así como la importancia que tienen los padres de los niños a lo largo del proceso interactivo con la televisión. De hecho, es en los albores de la presente década cuando el autor pone en la mesa, la discusión sobre la importancia que tiene la familia como grupo natural en donde el niño mira la televisión e indica que tanto los patrones de comunicación im- 
peran en cada familia, así como el valor y la legitimidad que para los padres tiene la pantalla chica; constituyen mediaciones múltiples en la interacción televisiva y, desde luego, repercuten en el tipo de apropiación que los niños hacen acerca de los programas televisivos que miran (Orozco, $1990 \mathrm{~b}$ ).

Los aportes generados por este investigador permiten apreciar que los contenidos televisivos son negociados por la audiencia televisiva; son también rechazados y sin que resulte excluyente, es posible que la audiencia transponga el sentido pretendido originalmente, en función de sus contextos particulares.

De esta manera, empleando una tipología de padres y madres (autoritarios, permisivos, aprensivos, activos, o represivos $)^{15}$ muestra cómo distintas "actitudes" de los padres y madres generan no sólo maneras diferentes de interactuar con la televisión, sino que se gestan procesos de aprendizaje distintos en los infantes.

\section{El psicodrama aplicado a la recepción televisiva}

A partir del eje de las multimediaciones propuesto por Orozco, otras investigaciones han ofrecido, desde su propia estrategia de acercamiento, importantes ángulos para avanzar en la comprensión de la llamada recepción televisiva. En particular, Inés Cornejo ha publicado diversos trabajos que, empleando el psicodrama corno herramienta de acercamiento, ha logrado que niños de distintas escuelas representen el entorno familiar ${ }^{16}$ con el propósito de recrear, desde la mirada de los niños, las condiciones que privan mientras ven la televisión; quién decide qué programa ver; la actitud de los padres cuando los niños ven televisión; la postura de los propios niños al interactuar con la TV; identificar los programas que les gustan; explorar el poder que ejercen los infantes sobre la TV y, busca correr un poco el velo sobre las actitudes y sensaciones

15 Orozco considera que en las familias hay estilos que los padres establecen para con la cantidad y calidad de la programación televisiva que los niños consumen, en este sentido establece que la familia permisiva muestra una completa tolerancia respecto de lo que los niños ven en la TV; la familia aprensiva está preocupada fundamentalmente por regular la cantidad de tiempo de exposición frente al aparato televisivo; la familia activa aplica formas de interlocución y diálogo con sus hijos a efecto de tamizar de una manera más directa lo que lo niños ven en el aparato receptor y, la familia represiva, emplea este medio como reforzador positivo o negativo, es decir, el encendido o apagado está supeditado al cumplimiento de normas establecidas por los padres o hermanos mayores en el hogar (Ver Orozco, 1990a).

16 Como lo menciona la autora, el psicodrama permite explorar el mundo familiar en el que los niños se desenvuelven. Este acercamiento es complementado con entrevistas en profundidad a docentes y directivos de las escuelas de interés 
que experimentan los niños ante los programas televisivos que miran (Cornejo, 1992).

Los reportes de Inés Cornejo permiten saber que algunos padres, dependiendo del estilo o tipología, emplean a la televisión corno medida de control para hacer que sus hijos cumplan con determinadas tareas o quehaceres domésticos; que la escena en la que los miembros de la familia se reúnen ante la televisión no estimula el intercambio verbal entre ellos; que el sector femenino se siente identificado con algún personaje de las telenovelas (Cornejo, 1992); que algunos niños tienen cierto poder para elegir los programas que han de mirar en la televisión; también se sabe que al llegar a casa los infantes -a veces a pesar de cierta vigilancia de las madres combinan sus tareas escolares con los momentos frente al televisor (Cornejo, 1994).

En un trabajo más reciente, ${ }^{17}$ Inés Cornejo -junto con Maritza Urteaga y Frank Viveros- busca ahondar en la dimensión sociofectiva del niño y su relación con la televisión. Aunque el interés de la investigadora consiste en explicar cuál es la normatividad que los maestros destilan respecto al uso que sus alumnos y alumnas deben aplicar con respecto a sus relaciones rutinarias con la televisión (Cornejo, et al., 1995), los datos ofrecidos permiten mirar diversas situaciones que suceden al interior de la familia de los infantes y, desde luego hace posible reconocer que también la escuela es un espacio de interlocución respecto a lo que el niño mira en la televisión. Veamos:

Las familias estudiadas, en términos de equipamiento doméstico poseen televisor, radio grabadora y cámara fotográfica; una proporción mayoritaria de las familias a las que pertenecen los infantes disponen de tecnología de punta, como cámaras de video, computadora, equipos de sonido con unidad para disco compacto y equipo para videojuegos interactivos.

En cuanto a la oferta de servicios para captar señales de televisión adicional, prácticamente ocho de cada diez familias estaban suscritas a los sistemas de las empresas Cablevisión o Multivisión y poco más de un 12\% disponían de antena parabólica. A pesar de contar con estos servicios, los estudiantes mencionaron programas televisivos que son captados mediante el sistema de televisión abierta. Esta situación hace concluir a los autores que "la oferta no

17 Los autores aplicaron una encuesta sobre equipamiento cultural doméstico a un total de 98 estudiantes inscritos en sexto grado en una escuela privada ubicada en la colonia Polanco. El cuestionario exploró ocupación de los padres, lugar de residencia, composición familiar, revistas preferidas, programas de televisión predilectos y otras actividades desarrolladas fuera de la escuela De acuerdo con los resultados, los ingresos familiares, en el 70\% de los casos, se movieron en un rango superior a los 30 salarios mínimos. Seis de cada diez familias estaban conformadas por 4 integrantes; un 23\% tenía 5 miembros y una de cada diez, estaba integrada por seis o más personas (Cornejo, et al., 1995) 
determina mecánicamente el consumo...” (Cornejo, et al., 1995:221). Asimismo, encontraron bajas preferencias por el género melodramático y cerca de la mitad de los niños encuestados expresaron preferencias por series norteamericanas y dos de cada diez contestaron que las caricaturas acaparaban su atención.

Al parecer, de acuerdo con la opinión de la directora de la escuela en donde se realizó el estudio referido, la televisión es empleada por los padres de los niños para recompensar o sancionar; según el cumplimiento de las responsabilidades escolares y de las tareas del hogar; de aquí que en el trabajo de investigación citado se concluya que la relación niño-televisión, ha de ser trasladada hacia el ámbito familiar con el propósito de explicar cómo la presencia o ausencia afectiva de los padres constituye un factor importante para dar cuenta de la permanencia física y emocional del escolar frente a la televisión (Cornejo, et al., 1995).

Los planteamientos de Cornejo permiten, por una parte, reconocer nuevamente el papel de las reglas y del poder que se fragua al interior de las familias no sólo al momento de encender el televisor sino antes y después de que ha sido apagado. Por otra, saca a flote la importancia de analizar el equipamiento cultural doméstico con el que cuenta cada familia y aún la necesidad de identificar otras fuentes de información a las que acceden los miembros de las familias con el propósito de establecer puntos de referencia que apunten el papel que pueden jugar elementos mediadores separados de la propia televisión. Amén de lo expuesto, considero cuatro elementos consustanciales respecto de la óptica ofrecida por la autora:

- Abre un camino que conlleva la importancia de darle la voz a los infantes para que desde su visión den cuenta de algunos aspectos actitudinales y situacionales de sus vidas domésticas; de cómo se tejen y destejen formas de control y contracontrol entre hijos y padres de familia.

- Pone de relieve la importancia de la actitud y las valoraciones que los padres y madres de familia tienen respecto de la televisión, de su contenido y del "tiempo frente al televisor",

- Fortalece la idea del papel que juegan los maestros de escuela y aún las autoridades de las mismas como elementos de interlocución de la recepción televisiva.

- Nos ha dejado mirar cómo las soledades de algunos infantes son habitadas por horas frente al televisor, dejando entrever -me parece- estructuras y dinámicas familiares como telón de fondo en las escenas infantiles. 


\section{Mediación materna}

En otro estudio, Martha Renero pone en el centro de su atención a la madre de familia como "el agente social de más peso en el ámbito doméstico y por ende, la interacción madre-hijos es el proceso más influyente en la recepción televisiva de estos últimos" (Renero, 1992: 33). La autora busca analizar cómo la mediación materna ${ }^{18}$ es capaz de crear, re-crear y articular diferentes prácticas de comunicación encaminadas a la supervivencia cultural de la institución familiar y cómo esta mediación ayuda a explicar las apropiaciones y aprendizajes que los niños derivan de su interrelación con la programación televisiva.

Poco más adelante, Martha Renero amplía su trabajo de investigación con el propósito de establecer comparaciones entre los usos y prácticas sociales que expresan madres televidentes de una ciudad fronteriza (Tijuana) en contraste con madres de la ciudad de México. Si bien es cierto que la autora toma como fuente de información a las madres, le interesa indagar tanto las prácticas y usos cotidianos que hacen éstas como el resto de los miembros de sus familias. Para Renero la madre es "una informante central acerca de los modos de ver la televisión y recepcionar otros medios de comunicación en la familia, independientemente si ésta tiene cónyuge o cumple el papel de jefe de familia (Renero, 1995: 130).

Mediante entrevista semiestructurada aplicada a más de 40 madres de familia de estas dos ciudades, la autora selecciona, en principio, dos tipos de familias: de un lado aquéllas cuya condición socioeconómica permite que sus hijos asistan a escuelas privadas y, del otro, aquéllas que de acuerdo con su posición, los hijos acuden a recibir educación en instituciones públicas.

Al realizar el análisis, Renero cruza esencialmente tres factores: i). condición socioeconómica, medida en función a la asistencia a la escuela pública o privada; ii). Condición sociocultural, considerada por la ubicación geográfica de las ciudades (una fronteriza y otra del centro del país y, iii). Equipamiento doméstico. Estos ejes le permiten explicar cómo estos dos tipos de audiencias familiares interactúan con la oferta televisiva; cuál es la apreciación que cada una tiene respecto de la oferta a la que tiene acceso y por qué a mayor competencia cultural los televidentes generan prácticas televisivas distintas. En detalle, a continuación se anotan algunos de los hallazgos que más interesan en este trabajo.

18 Martha Renero inscribe su trabajo dentro de la propuesta generada por Guillermo Orozco sobre la categoría de mediación. Su aportación consiste en aproximarse a las prácticas de la mediación de la familia y la escuela en el proceso de recepción televisiva de los niños mexicanos. 
Martha Renero considera que la capacidad de acceder a una escuela de educación privada implica una mayor disponibilidad en tres aspectos de competencia escolar: acceso a conocimiento especializado, dominio de discursos formales eruditos y familiaridad con clasificaciones culturales elaboradas. Un aspecto importante dentro de los hogares estudiados es la posesión de tecnologías, empezando por el número de televisores y su ubicación.

La mayoría de las madres de familia, cuyos hijos asisten a escuelas públicas, dijeron tener solamente un televisor en casa y éste se localizaba física y simbólicamente en la sala -generalmente habilitado para recibir visitas, o bien frente a la mesa del comedor o frente a las camas cuando la casa era de una sola pieza. En cuanto a los gustos matemos parecen estar fuertemente mediados por los gustos de su familia, tal parece que las madres no tienen preferencias claramente marcadas, excepto en el género melodramático.

Referente a gustos y credibilidad hacia los programas y noticieros televisivos, el estudio muestra una gran diferencia entre las madres de audiencia de educación pública que prefieren las telenovelas del canal 2 de Televisa, al considerar que les aportan elementos de enseñanza para sus hijas y ellas mismas sobre diversas situaciones de la vida y una gran parte cree que son historias reales que pueden suceder a cualquiera. También reportó alta preferencia por parte de las madres, el canal 5, específicamente por los programas del género policiaco y caricaturas; el canal 4 es objeto de selección por las películas y programas deportivos que transmite.

En cuanto a los noticieros, la credibilidad está asociada con la personalidad e imagen de los conductores y la capacidad de testimonio -coincidencia entre imagen y discurso-, por eso gran parte de las madres de esta audiencia señalaron que le creen a Jacobo Zabludovsky por identificarlo como una persona con reputación y muchos años en el medio. Otras madres dijeron que lo ven porque es el único canal que se ve en sus hogares o por ser en castellano; algunas madres de la frontera no hablan el idioma inglés de sus vecinos cercanos- (Renero, 1995).

En contraste, con los hogares que acuden a escuelas privadas, el número de televisores es en promedio de tres a cuatro, gracias a la capacidad de compra y uso de tecnología de punta; la ubicación de estos aparatos es como sigue: uno en la recámara de los niños, complementado con otro para practicar videojuegos; uno más en la recámara de los papás --con acceso a canales cancelados para los niños; uno más en la sala o en el estudio y otro más (a veces portátil, en blanco y negro) dispuesto en el cuarto de la servidumbre o en la cocina. Al parecer, esta ubicación en lugares íntimos le da un sentido más personalizado en este tipo de audiencias. 
En este tipo de audiencias, es común que la video grabadora se use como "niñera", cuando las madres están ausentes u están ocupadas; en cuanto a los gustos televisivos, las madres informaron que son muy diferenciados entre las nuevas y viejas generaciones; cada quien elige sus programas y los momentos de recepción televisiva conjunta son más bien escasos. En cuanto a la comunicación conyugal es más frecuente con las madres que tienen menor número de televisores que con las que cuentan con tres o más. (Renero, 1995).

Las madres de la audiencia de educación privada y los miembros de sus familias aplican criterios de calidad o recomendaciones de amistades a fin de seleccionar los programas, siempre buscan poseer lo más moderno en tecnologías y señales, colección de videos dé estreno y lo mejor de eventos internacionales -previo pago extra-; de esta manera manifestaron desprecio por los canales 2 y 4 de Televisa cuya programación la consideran propia para el entretenimiento de las mayorías que reciben la señal gratuitamente. Aquí se muestra una diferencia entre las madres de Tijuana y las del Distrito Federal porque las primeras ven gran parte de la programación en inglés y el resto en español pero de programas realizados en los Estados Unidos de Norteamérica para hispanos o doblados al castellano. En cuanto a los noticieros, una parte de esta audiencia -localizada en la frontera- dijeron ver los que se producen y trasmiten desde el país del norte, por considerar que al no tener compromisos con el gobierno mexicano son más reales y verídicos. A diferencia de las madres de esta misma audiencia que viven en el D.F. pero que no ven sino canales en español -de Televisa- pero bajo críticas constantes e incredibilidad a los noticieros. (Renero, 1995).

La mayoría de las madres entrevistadas coinciden en reprobar la violencia televisiva que perjudica a los niños, debido a que han observado la agresividad en las caricaturas. En las audiencias que acuden a escuelas de régimen privado, los niños imitan modelos o modos de interactuar, formas de vestir y actitudes no convenientes para su edad. A este respecto, las madres de familia dicen que se debe a lo fantasiosa y a la credibilidad que otorgan los niños a esos programas; algunas madres de la audiencia de educación pública mostraron su rechazo a las escenas de sexo que inundan la pantalla sobre todo por las noches, situación que a las madres de la otra audiencia, si bien expresaron preocupación, no fue objeto de referencia constante. (Renero, 1995).

La autora concluye que las madres de audiencia de escuelas privadas de ambas ciudades observan una práctica de recepción más motivada por expectativas de ascenso social, acompañada por la deliberada actividad selectiva de la TV y otros medios; de igual manera destaca que únicamente quienes poseen mayor nivel de información, acceso a las escuelas de paga para los hijos y 
que generalmente son las de mayores y más modernos recursos tecnológicos, hacen críticas más constantes al sistema institucional de producción de la televisión comercial mexicana actual.

Entre los padres de familia de la audiencia de escuelas privadas de las dos ciudades, aunque principalmente de la capital, se advierte una postura ciudadana de exigencia para que la institución televisiva ofrezca una programación más variada y de mayor calidad que cubra las necesidades de entretenimiento e información para el público cada vez más exigente (Renero, 1995: 152).

En los esfuerzos de Renero priva la necesidad de explicar la llamada centralidad de la madre de familia como agente mediador de la recepción televi$\operatorname{siva}^{19}$. Es evidente que está interesada en un estadio de la familia, es decir, en tanto los hijos son menores y por ende la madre figura como principal "conocedora” de los hábitos de sus retoños. Mi planteamiento es que en ciclos más avanzados en la familia, la madre pierde terreno en esa centralidad y deja de crear, recrear y articular una buena parte de las prácticas de comunicación debido al desarrollo y reacomodo de los miembros de las familias, aspecto que exige emprender trabajos de investigación con estructuras y estadios familiares diferentes.

En otro sentido, las reflexiones derivadas de sus trabajos en tomo a la condición socioeconómica como elemento generador de competencias culturales diferenciadas entre los televidentes, la consideración del género como punto diferenciador de la preferencias y prácticas televisivas y la ubicación sociocultural en la que se colocan las familias aportan valiosos elementos de juicio para iluminar algunas oquedades de lo que sucede con la televisión en el espacio privado, al tiempo que señalan la trascendencia de contar con estos elementos para ofrecer una mejor comprensión del fenómeno que nos ocupa.

\section{Vida cotidiana, género, televisión y familia}

Recientemente, con el propósito de explorar la relación entre televisión y vida cotidiana en sectores populares de la ciudad de México, Miguel Ángel Aguilar, Ana Rosas Mantecón y Verónica Vázquez llevaron a cabo una investigación basada en la aplicación de entrevistas colectivas a grupos focales (grupos de enfoque) en los que convocaron a los miembros de las distintas familias del Distrito Federal, considerados como grupos de clase media baja, de

19 Como lo escribiría la autora en uno de sus primeros trabajos publicados en los cuadernos del PROIICOM “tele-viciva”, aludiendo al "tele-vicio" o tiempo excesivo de los infantes frente a la pantalla chica. Ver Renero, 1992. 
acuerdo con los criterios establecidos por los estudios mercadológicos. ${ }^{20}$ Esta investigación permitió apreciar que por regla general son las madres, los ancianos y los niños los que pueden ser encontrados en el hogar entre semana; la presencia de los hombres jóvenes y de los padres se registra por las noches (Aguilar, et al., 1995).

Ciertamente, durante la primera parte del día, el orden doméstico está normado por la madre y, al llegar el cónyuge masculino, es él quien activamente marca pautas y tiempos de actividad, entre los que destaca ver televisión. Así, la televisión encendida presencia las labores de la casa en tanto las madre-esposas espasmódicamente atienden los mensajes de la televisión, circunscribiendo su función a un radio con pantalla. Por las tardes, los miembros que permanecen en el hogar pueden suspender algunas de sus actividades para ver la televisión, y es frecuente que se coma con la televisión prendida (Aguilar, et al., 1995).

En términos generales, en una jornada promedio, los autores estimaron que la pantalla televisiva --en hogares de clase media baja-, se prende a las 7:00 para ver noticias; quienes permanecen en el hogar continúan viendo la oferta matutina, hacen un alto para ir a comprar comestibles y van por los niños a la escuela; al llegar, los pequeños encienden el televisor para ver caricaturas hasta que inician las telenovelas, mismas que registran la presencia de niños, mujeres mayores, ancianas, mujeres adolescentes y con cierta eventualidad, cónyuges masculinos.

Los fines de semana (sábados y domingos), los investigadores observaron que la televisión pierde atractivo para las mujeres pues generalmente las transmisiones de partidos de fútbol, las luchas, box, programas de comentarios deportivos, encuentros de básquetbol, béisbol y ciclismo; aglutinan a niños, jóvenes adolescentes y adultos masculinos. Durante estos dos días de la semana, las rentas de películas videograbadas operan como una opción capaz de reunir a la mayor parte de la familia para ver largometrajes de terror, acción, cómicas y policiacas (Aguilar, et al., 1995).

De acuerdo con el estudio referido, los investigadores ofrecen un análisis secta rizado acerca de las familias estudiadas; estrategia que permite apreciar los gustos e inclinaciones de cada uno de estos grupos y, por supuesto, ofrece

20 Este tipo de estudios son identificados con las siglas BIMSA y establecen que la clase media baja presenta ingresos que pueden ir de uno a nueve salarios mínimos Como lo señalan los autores, una vez delimitadas las familias en función del ingreso, se procedió a integrar los grupos de enfoque a par lir de las variables sexo, edad y lugar de residencia. De esta manera se integraron grupos homogéneos de nueve personas según estas variables y el rol familiar, es decir, las sesiones de entrevistas focales se aplicaron a abuelos, abuelas, tíos, tías, padres, madres e hijos de distintas edades (Aguilar, et al, 1995) 
una lectura interesante acerca de la manera en que opera la audiencia familiar. Enseguida una breve referencia a los aspectos de mayor interés encontrados en este reporte.

Las madres declararon preferir las telenovelas, seguidos por las series y por los programas de opinión que abordan problemas cotidianos; como lo apuntan los autores, en particular las telenovelas parecen constituir "toda una institución de educación sentimental, que permite al auditorio poner en juego su propia afectividad, sublimar deseos de transgresión e identificarse con las víctimas" (Aguilar, et al., 1995: 138). Si bien es cierto que es ampliamente conocido el hecho de que la gran mayoría de las telenovelas se han escrito alrededor de la multi-repetida historia de la cenicienta, la investigación aquí comentada subraya que las madres gustan del conocimiento anticipado de lo que ocurrirá y, como alguna de las entrevistadas lo expresó: “aunque la trama sea la misma nos gusta verla con otras artistas. Es como una canción. Hay diferente formas de interpretarla" (Aguilar, et al., 1995: 138-139).

Los padres parecen estructurar el contacto con la televisión en tiempos claramente delimitados: por las mañanas y la noche (entre semana); buscan noticias, series, películas y partidos de fútbol que al efecto se trasmiten. Los fines de semana, como se ha señalado con anterioridad, se aprecia una fuerte lealtad a las transmisiones deportivas, series de acción y largometrajes. En detalle, se pudo apreciar que este sector de la audiencia familiar expresa juicios severos cuando los programas referentes a comentarios sobre jornadas deportivas no están plenamente argumentados o bien muestran sesgo deliberado en favor de algún equipo. En otras palabras, los padres parecen estar pendientes no sólo de la objetividad con que se comentan los encuentros deportivos, sino que además evalúan diversos aspectos formales.

En las familias de este sector socioeconómico, los adolescentes son los que expresaron ver menos televisión; condición comprensible si se tiene en cuenta que debido a la edad muchos de sus intereses y actividades están fuera del hogar. No obstante, su vínculo con la televisión se concreta con deportes, series y musicales. En paralelo, estos jóvenes muestran proclividad a grabar videoclips, antologías personales de música e imágenes de sus grupos y artistas favoritos, es decir, refuncionalizan el uso de la televisión (Aguilar, et al., 1995).

Las adolescentes, junto con sus madres y hermanos menores, constituyen parte de la escena familiar con la televisión, sobre todo cuando se transmiten caricaturas, telenovelas, series y películas. Un aspecto por demás interesante es que el estudio reporta que frecuentemente las adolescentes tienden a incorporar a sus respectivos novios a ver la televisión. También notaron preferencias por el género telenovela, aunque, a diferencia de las madres, parecen 
mantener una posición crítica respecto a las historias que nutren los melodramas; otros programas de su preferencia son los de humor las luchas, películas de terror y las series norteamericanas. ${ }^{21}$ (Aguilar, et al., 1995).

Las caricaturas de héroes galácticos, las series norteamericanas y los programas de concurso constituyen la oferta pro gramática que más niños convoca al interior de la familia. Sin embargo, también muestran alta asiduidad al género de las telenovelas pues comparten con sus respectivas madres estos tiempos frente al televisor y éstas a su vez, muestran inclinaciones por el género de las caricaturas.

Las niñas expresaron especial interés por las telenovelas y sus comentarios durante las entrevistas focales permitieron a los autores colegir que comparten muchas de las motivaciones de sus respectivas madres y hermanas mayores, cuando miran-comentan el desarrollo de este tipo de historias melodramáticas. Es frecuente la inclinación por los programas de dibujos animados, los de baile y concurso así como las series norteamericanas, pero a diferencia de otros sectores como las adolescentes y las madres, externaron gozar de los programas de lucha libre en compañía de sus papás y hermanos (Aguilar, et al., 1995).

Así, en esta investigación resultan claves tres elementos. Primero, el hecho de reconocer que al interior del grupo privado conviven géneros y generaciones desde los cuales se trazan distintas preferencias televisivas; usos que responden a los intereses etáreos y rutinarios de cada uno de los integrantes de las familias y, desde luego, contribuye a explicar una múltiple concurrencia de prácticas alrededor de la televisión. Segundo, la multiplicidad de intereses e interacciones con la pantalla chica reclaman a las familias cierta organización y procesos de negociación manifiestos o implícitos para hacer posible la articulación cotidiana con la televisión en particular, y con el resto de actividades en general. Tercero, permite ahondar en el complejo entramado del poder, visto que se marcan tiempos y condiciones en el que la toma de decisiones puede estar circunscrita a las madres de familia o bien a los niños, pero durante el último tercio del día o, de manera expansiva, en los fines de semana, el dominio se desplaza y se concentra en los padres y/o en los integrantes de género masculino.

Una de las consideraciones finales que hace el estudio referido es que "la familia se convierte en una determinante comunidad de apropiación del medio. La dinámica familiar -a partir de cada miembro- explica en buena medida la selección de géneros o programas y los diferentes usos de la televisión" (Aguilar, et al., 1995:150).

21 En particular se hace mención del programa Beverly Hills porque en él se tratan problemas de drogas, sexo y divorcio; temas que interesan a las adolescentes. 


\section{Sumario}

Con este breve recorrido sobre el binomio televisión y familia, he pretendido ofrecer una visión general, de las principales vertientes teórico metodológicas generadas por los investigadores. En paralelo, he tratado de subrayar los principales avances que en la materia se han dado, y ofrecer elementos que permitan comprender cómo es que se han incorporado paulatinamente un mayor número de elementos socioculturales, contextuales y situacionales para ofrecer una más amplia comprensión del fenómeno que nos ocupa. Como resultado, concluyo lo siguiente:

* Al inicio de la década de los setenta se registran los primeros esfuerzos encaminados a tratar de investigar a la audiencia televisiva en su contexto familiar.

* A lo largo de los años ochenta se registra un creciente interés en el tema televisión y familia. James Lull (1988), Irene Goodman (1983), Hope Jensen (1985), David Morley (1986), Martín- Barbero (1986) y Guillermo Orozco (1987) entre otros, constituyen, mediante sus esfuerzos y avances propios, las puntas de lanza que hicieron posible que comunicólogos, antropólogos, sociólogos y psicólogos redimensionaran la importancia de analizar e investigar a la televisión y en general a los medios de comunicación dentro del hogar desde una perspectiva multidisciplinaria.

* En Latinoamérica, Martín-Barbero (1986) y Guillermo Orozco (1987), desde sus propuestas específicas derivadas de la teoría de la mediación, han sido los impulsores de importantes vertientes que han contribuido no sólo a mejorar la comprensión sobre el fenómeno televisivo sino que representan valiosos puntos de referencia para comprender otros trabajos de investigación producidos y publicados principalmente en Brasil, Colombia, Perú, Venezuela y México.

* Irene Goodman (1983) es una de las primeras investigadoras que llama la atención sobre la trascendencia de estudiar procesos de comunicación teniendo en cuenta que las familias constituyen sistemas y que en tal sentido éstas viven ciclos; generan y transforman reglas y dinámicas que en mucho conforman el telón de lo que otros estudiosos han encontrado alrededor de la televisión.

* Por su parte, Leoncio Barrios (1992) no sólo ha ofrecido una explicación del papel educativo que puede tener la televisión sino que además ha marcado algunos matices respecto del denominado poder masculino en el hogar, dado que en dos de las familias investigadas por él, de estructura monoparental femenina, los hombres que conforman estas familias se repliegan 
al poder femenino aun a pesar de haber alcanzado edades maduras y de conformar familias propias. Asimismo, el autor ha explicado parte de los usos del televisor en función de la dinámica familiar.

* La referencia a los espacios físicos en los hogares y su significado en términos de la relación con la televisión y con las pautas de interacción entre los integrantes de las familias, han permitido redimensionar significados y funciones diferenciales en los espacios que arropan el escenario privado, aspecto que sin duda alguna marca una constante en la documentación de este tipo de estudios.

* En lo que va de la presente década los estudios sobre el tema han tenido en cuenta la caracterización de familias por su estructura (nucleares o extensas, biparentales o monoparentales), por su nivel socioeconómico (clase media, clase alta, populares), por su residencia (rural o urbana); han documentado las características de los hogares en los que habitan las familias (número de habitaciones, funciones de los espacios, equipamiento doméstico) y han ofrecido los perfiles de quienes integran a las familias, en términos de edad, sexo, formación educativa, empleo (remunerado o no remunerado), rutinas, hábitos y preferencias.

* Con dichos elementos, hoy sabemos que en las familias, privan reglas, usos, preferencias; que desencadenan tomas de decisiones que simbolizan procesos de poder en el que -para algunos casos- se reproducen amplios procesos socioculturales en los que el género masculino refuerza pautas de dominio con respecto a las mujeres, pero en otras estructuras familiares, el poder se concentra matri -linealmente.

* Sabemos que "ver televisión" no implica -necesariamente- un momento frente al televisor sino acaso más una serie de múltiples comportamientos y de procesos transicionales que desbordan con mucho esa imagen que todavía se asocia cuando se alude al hecho de "ver televisión",

* Se tiene claro que el espacio doméstico, o, si se quiere, el hogar, tiene distintos significados entre los padres y las madres de familia y que esta condición conlleva distintas prácticas de expectación (Morley, 1986) determinadas genérica y generacionalmente.

* En su mayoría, con cierta independencia de los enfoques teóricos y estrategias de investigación (etnográficas, entrevistas focales, entrevistas en profundidad y/o cuestionarios), se puede decir que los investigadores latinoamericanos y de otros países se han preocupado, fundamentalmente, por explicar reglas, usos, procesos de toma de decisiones (poder) y preferencias televisivas generadas en distintos tipos de familias. De manera particular, tanto las reglas como el poder familiar y en particular respecto de la televisión constituyen denominadores comunes en los trabajos referidos. 


\section{Bibliografía}

Aguilar, Miguel Angel, et. al., 1995 “Televisión y vida cotidiana Una aproximación cualitativa”, en Versión No. 5. México: UAM-Xochimilco.

Barrios, Leoncio, 1992: Familia y televisión. Venezuela: Monte Ávila Editores Latinoamericana.

Cornejo Portugal, Inés, 1992: "El psicodrama aplicado al estudio de la recepción familiar televisiva”, en Comunicación y sociedad. No. 14-15. México: CEIC- Universidad de Guadalajara.

Cornejo Portugal, Inés, 1994: “¿Cómo la ves? El psicodrama aplicado para el estudio de la recepción televisiva de los niños”. En Televidencia. Perspectivas para el Análisis de Recepción Televisiva. México: UIA, PROIICOM.

Cornejo Portugal, Inés, et. al., 1995: “Televisión sí, pero con orden”, en Anuario de investigación de la comunicación. CONEICC II. México: CONEICC.

Covarrubias, Karla Yolanda, et. Al., 1994: Cuéntame en qué se quedó. La novela como fenómeno social. México: Trillas.

Fenichel, Otto, 1979: Teoría psicoanalítica de la neurosis. Argentina: Paidós

Goodman, Irene, 1983: “Tv's Role in Family Interaction” en: Journal offamily issues, Vol. 4, Núm 2.

Jensen, Hope. et. al., 1985: "Family contexts of television" en: ECTJ. Vol. 33, No. 1.

Leichter, H, et. al., 1985: "Family Contexts of Television" en: Educational communicational and technology journal. No. 33.

Llano, Clara, 1992: "Usos sociales de la televisión y de la telenovela. La telenovela en el barrio popular”, en Martín-Barbero y Sonia Muñoz, (coord). Televisión y melodrama. Colombia: Tercer mundo, editores.

Lull, James, 1980: "The social uses of television" en: Human communication research. Vol. 6, No. 3.

Lull, James, 1990: Inside family wiewing. Ethnographic Research on Television's Audiences. London and New York: Routledge, Eds.

Lull, James, 1992: "Recepción televisiva, reforma y resistencia en China. Un estudio etnográfico”, en: Orozco, Guillermo (comp). Hablan los televidentes. Estudios de recepción en varios paises. México: Iberoamericana.

Lull, James, 1992: "La estructuración de las audiencias masivas", en Dia-logos de la comunicación, No. 32. Perú: FELAFACS.

Martín-Barbero, Jesús y Sonia Muñoz, 1992: Televisión y melodrama. Colombia: Tercer mundo, editores. 
Morley, David, 1992: Television, audiences \& cultural studies. Great Britain: Routledge.

Morley, David y Silverstone, Roger, 1994: "Comunicación y contexto. Perspectivas etnográficas sobre la audiencia de medios”, en: Versión No. 4. México: UAM-Xochimilco.

Morley, David, 1986: Family television. Cultural power and domestic leisure. Great Britain: Comedia.

Orozco, Guillermo, 1990a: "Practicas de mediación de la familia y la escuela en la recepción televisiva de los niños", en: Proyecto de Investigación del Programa Institucional en comunicación y Practicas Sociales. Mecanograma. México: UIA, PROIICOM.

Orozco, Guillermo, 1990b: "No hay una sola manera de hacer televidentes", en Estudios sobre culturas contemporáneas. Vol. IV No. 10. México: Universidad de Colima.

Orozco, Guillermo, 1991a: Recepción televisiva. Tres aproximaciones y una razón para su estudio. México: UIA, PROIICOM.

Orozco, Guillermo, 1992: "Familia, televisión y educación en México. La teoría educativa de la madre como mediación en la recepción televisiva de los niños, en: Orozco, Guillermo (comp): Hablan los televidentes... Op. Cit.

Renero Quintanar, Martha, 1992: "La mediación familiar en la construcción de la audiencia. Prácticas de control materno en la recepción "tele-viciva” infantil” en: Orozco, Guillermo (comp). Hablan los televidentes... Op. Cit.

Renero Quintanar, Martha, 1995: "Audiencias selectivas en el entorno de la oferta multiplicada; el discurso materno acerca de los usos de la televisión y otros medios", en Comunicación y sociedad No. 24. México: Departamento de Estudios de la Comunicación social, Universidad de Guadalajara.

Segura Escobar, Nora. (1992) "Usos sociales de la televisión y de la telenovela. La familia frente a la televisión: Hábitos y rutinas de consumo en Cali” en: Martín-Barbero, Jesús y Sonia Muñoz (Coord) Televisión y melodrama. Colombia, Tercer Mundo Editores.

Uribe B, Ana (1993) "La Telenovela en la Vida Familiar Cotidiana" en: Estudios sobre las culturas contemporáneas. Vol. V/ Número 15. Colima, México: Universidad de Colima. 